\title{
Profiles of coronary blood flow velocity in patients with aortic stenosis and the effect of valve replacement: a transthoracic echocardiographic study
}

\author{
Antoinette Kenny, Christopher R Wisbey, Leonard M Shapiro
}

\begin{abstract}
Objective-To report the first non-invasive assessment by transthoracic Doppler echocardiography of coronary blood flow in patients with aortic stenosis and of the effects of valve replacement.

Design-High frequency transthoracic Doppler echocardiography was used to examine resting phasic flow in the left anterior descending coronary artery before and after replacement of the aortic valve in awake, unsedated patients with pure aortic stenosis and normal coronary arteries.

Setting-A tertiary referral cardiothoracic centre.

Methods-Eleven patients with pure aortic stenosis and normal coronary

patients with aortic stenosis and preoperative clinical history, transvalvar gradient, left ventricular mass index, or ventricular dimensions.

Conclusions-Coronary flow profiles in patients with aortic stenosis were characterised by reversed early systolic flow and delayed forward systolic flow and attainment of peak diastolic velocity. Reversal of these abnormalities by replacement of the aortic valve may reflect altered left ventricular and aortic haemodynamics and contribute to the relief of angina when left ventricular hypertrophy persists. Further studies may correlate abnormalities of coronary flow with preoperative clinical and haemodynamic state.
\end{abstract} arteries (six men, five women, mean (range) age 69 (50-82) years), were studied the day before and 1 week after replacement of the aortic valve. These patients were selected from a cohort of 15 due to ease of imaging of the left anterior descending coronary artery. Seven had a history of angina. Haemodynamics, peak transvalvar aortic gradient, left ventricular mass index, ventricular dimensions, and profiles of coronary flow velocity were measured. Profiles of coronary flow velocity were also measured in a control population of 10 normal subjects (five men, five women, mean (range) age 58 (34-66) years).

Results-The control population showed forward flow throughout systole, but reversed early systolic flow (mean velocity $20.6(3.6) \mathrm{cm} / \mathrm{s})$ was seen in six patients with aortic stenosis. Only three of these patients had a clinical history of angina. Peak and mean systolic and diastolic forward flow velocities were not significantly different in the control group and in patients with aortic stenosis. The time from the start of systole to the onset of forward systolic flow was significantly longer in patients with aortic stenosis than in the control population (185 (8.5) $v 85$ (10) ms, p $<0.01)$. The time from the onset of diastolic flow to peak diastolic velocity was also significantly longer in the aortic stenosis group (146 (16) $v 74$ (13) ms, p < 0.01). These abnormalities in profiles of coronary flow were reversed by replacement of the aortic valve. There was no correlation between changes in flow profiles in
(Br Heart f 1994;71:57-62)

Aortic stenosis in the presence of angiographically normal coronary arteries is often accompanied by clinical, electrocardiographic and histological findings suggestive of myocardial ischaemia. ${ }^{1}$ The incidence of angina in patients with significant aortic stenosis has been reported to be between $40 \%$ and $80 \% .^{2-4}$ Considerable limitation of coronary reserve, attributed to left ventricular hypertrophy, may contribute to myocardial ischaemia in these patients..$^{5-7}$ Replacement of the aortic valve, however, relieves angina in the immediate postoperative period without regression of left ventricular hypertrophy. An imbalance between myocardial oxygen supply and demand due to decreased coronary perfusion pressures and increased left ventricular wall tension may also be implicated in the pathogenesis of angina in patients with aortic stenosis. ${ }^{38}$ Such alterations in aortic and left ventricular pressures may influence dynamics of the phasic left coronary artery flow.

There have been no reports of coronary flow patterns in awake, unsedated humans with aortic stenosis. Invasive studies of coronary flow in patients with pure aortic stenosis have been performed in six patients during cardiac surgery with epicardial Doppler techniques and in two patients during cardiac catheterisation with an intravascular Doppler flow probe. ${ }^{910}$ These techniques, however, are invasive and may not accurately reflect the dynamics of resting coronary blood flow in these patients.

Methodological limitations have until recently prevented non-invasive assessment of 
Table 1 Characteristics and haemodynamics of patients who underwent aortic valve replacement

\begin{tabular}{|c|c|c|c|c|c|c|c|c|c|c|c|c|c|c|c|c|c|c|c|c|c|c|}
\hline \multirow[b]{2}{*}{ Sex } & \multirow[b]{2}{*}{ Age } & \multirow[b]{2}{*}{ Angina } & \multirow[b]{2}{*}{$R S F$} & \multirow[b]{2}{*}{$A V G$} & \multirow[b]{2}{*}{$L V M I$} & \multirow[b]{2}{*}{ LVH† } & \multicolumn{8}{|c|}{ Before } & \multicolumn{8}{|l|}{ After } \\
\hline & & & & & & & $H R$ & $M A P$ & $T S F$ & $D T P$ & $S V P$ & $S V m$ & $D V p$ & $D V m$ & $H R$ & $M A P$ & $T S F^{\star \star}$ & ${ }^{*} D T P^{\star *}$ & * $S V p$ & $S V m$ & $D V p$ & $D V m$ \\
\hline $\begin{array}{l}\mathbf{F} \\
M\end{array}$ & $\begin{array}{l}73 \\
73\end{array}$ & $\overline{+}$ & + & $\begin{array}{r}100 \\
72\end{array}$ & $\begin{array}{l}322 \\
287\end{array}$ & $\begin{array}{r}12 \\
6\end{array}$ & $\begin{array}{l}74 \\
63\end{array}$ & $\begin{array}{r}97 \\
110\end{array}$ & $\begin{array}{l}210 \\
200\end{array}$ & $\begin{array}{l}250 \\
170\end{array}$ & $\begin{array}{r}-14 \\
-24 \\
15\end{array}$ & $\begin{array}{r}-12 \\
-16 \\
10\end{array}$ & $\begin{array}{l}60 \\
37\end{array}$ & $\begin{array}{l}34 \\
23\end{array}$ & $\begin{array}{r}103 \\
93\end{array}$ & $\begin{array}{r}95 \\
103\end{array}$ & $\begin{array}{r}100 \\
80\end{array}$ & $\begin{array}{l}30 \\
30\end{array}$ & $\begin{array}{l}18 \\
26\end{array}$ & $\begin{array}{l}17 \\
20\end{array}$ & $\begin{array}{l}43 \\
38\end{array}$ & $\begin{array}{l}33 \\
28\end{array}$ \\
\hline $\mathbf{F}$ & 73 & - & + & 80 & 122 & 9 & 75 & 100 & 200 & 120 & $\begin{array}{r}-15 \\
16\end{array}$ & $\begin{array}{r}-10 \\
12\end{array}$ & 41 & 30 & 72 & 100 & 80 & 140 & 21 & 14 & 40 & 28 \\
\hline $\begin{array}{l}\mathbf{M} \\
\mathbf{F} \\
\mathbf{M} \\
\mathbf{M} \\
\mathbf{F}\end{array}$ & $\begin{array}{l}63 \\
80 \\
82 \\
50 \\
64\end{array}$ & $\begin{array}{l}+ \\
+ \\
+ \\
+ \\
+\end{array}$ & $\frac{\bar{t}}{\overline{+}}$ & $\begin{array}{r}120 \\
130 \\
48 \\
82 \\
116\end{array}$ & $\begin{array}{l}203 \\
359 \\
271 \\
-148\end{array}$ & $\begin{array}{r}7 \\
6 \\
13 \\
7 \\
9\end{array}$ & $\begin{array}{l}53 \\
75 \\
89 \\
67 \\
60\end{array}$ & $\begin{array}{r}135 \\
83 \\
87 \\
107 \\
113\end{array}$ & $\begin{array}{l}210 \\
190 \\
\overline{140} \\
200\end{array}$ & $\begin{array}{l}180 \\
170 \\
140 \\
150 \\
110\end{array}$ & $\begin{array}{r}14 \\
11 \\
-17 \\
13 \\
-33 \\
16\end{array}$ & $\begin{array}{r}9 \\
10 \\
-12 \\
11 \\
-26 \\
12\end{array}$ & $\begin{array}{l}30 \\
37 \\
31 \\
37 \\
48\end{array}$ & $\begin{array}{l}20 \\
25 \\
20 \\
26 \\
32\end{array}$ & $\begin{array}{l}62 \\
87 \\
84 \\
63 \\
90\end{array}$ & $\begin{array}{r}130 \\
87 \\
83 \\
100 \\
113\end{array}$ & $\begin{array}{r}150 \\
60 \\
-\quad \\
70 \\
90\end{array}$ & $\begin{array}{r}100 \\
70 \\
60 \\
60 \\
60\end{array}$ & $\begin{array}{r}15 \\
10 \\
17 \\
7 \\
10\end{array}$ & $\begin{array}{r}12 \\
8 \\
3 \\
5 \\
8\end{array}$ & $\begin{array}{l}26 \\
35 \\
40 \\
27 \\
24\end{array}$ & $\begin{array}{l}18 \\
25 \\
29 \\
19 \\
16\end{array}$ \\
\hline $\begin{array}{l}\mathbf{M} \\
\mathbf{M} \\
\mathrm{F}\end{array}$ & $\begin{array}{l}79 \\
58 \\
63\end{array}$ & $\begin{array}{l}+ \\
+ \\
-\end{array}$ & $\bar{z}$ & $\begin{array}{r}55 \\
63 \\
110\end{array}$ & $\begin{array}{l}\overline{240} \\
395\end{array}$ & $\begin{array}{l}9 \\
3 \\
9\end{array}$ & $\begin{array}{r}73 \\
113 \\
60\end{array}$ & $\begin{array}{r}133 \\
93 \\
90\end{array}$ & $\frac{160}{160}$ & $\begin{array}{r}30 \\
140 \\
140\end{array}$ & $\begin{array}{r}12 \\
-30 \\
14\end{array}$ & $\begin{array}{r}9 \\
-\quad 21 \\
12\end{array}$ & $\begin{array}{l}36 \\
39 \\
36\end{array}$ & $\begin{array}{l}28 \\
25 \\
28\end{array}$ & $\begin{array}{l}75 \\
83 \\
60\end{array}$ & $\begin{array}{r}117 \\
93 \\
107\end{array}$ & $\frac{140}{40}$ & $\begin{array}{l}20 \\
90 \\
90\end{array}$ & $\begin{array}{l}19 \\
12 \\
20\end{array}$ & $\begin{array}{l}15 \\
11 \\
18\end{array}$ & $\begin{array}{l}46 \\
32 \\
33\end{array}$ & $\begin{array}{l}34 \\
25 \\
26\end{array}$ \\
\hline
\end{tabular}

${ }_{\star \star} \mathrm{p}<0.01$ by Wilcoxon signed rank paired test between before and after values.

tLeft ventricular hypertrophy; Estes score.

RSF, reversed systolic flow; AVG, peak transvalvar gradient ( $\mathrm{mm} \mathrm{Hg})$; LVMI, left ventricular mass index ( $\left.\mathrm{g} / \mathrm{m}^{2}\right)$; HR, heart rate (beats/min); $\mathrm{MAP}$, mean arterial pressure (mm Hg); TSF, time from onset of systole to forward systolic flow (ms); DTP, time from onset of diastolic flow to peak flow (ms); SVp, peak systolic velocity $(\mathrm{cm} / \mathrm{s}) ; \mathrm{SVm}$, mean systolic velocity $(\mathrm{cm} / \mathrm{s}) ; \mathrm{DVp}$, peak diastolic velocity $(\mathrm{cm} / \mathrm{s}) ; \mathrm{DVm}$, mean diastolic velocity $(\mathrm{cm} / \mathrm{s})$.

patterns of coronary blood flow in patients with aortic stenosis. It is now possible to image and measure blood flow velocities in the distal left anterior descending coronary artery (LAD) with high frequency transthoracic Doppler echocardiography. ${ }^{11} 12$ We used this non-invasive technique to characterise profiles of blood flow velocity in the $\mathrm{LAD}$ under physiological conditions, before and after valve replacement in patients with aortic stenosis.

\section{Patients and methods \\ PATIENTS}

Eleven patients with pure aortic stenosis admitted for elective replacement of the aortic valve were studied. All had angiographically normal coronary arteries. These patients were selected from a group of 15 because of ease of imaging of the LAD. There were six men and five women; the mean (range) age was 69 (50-82) years. Seven had symptoms of angina pectoris and all had dyspnoea on exertion or dizziness. All patients had electrocardiographic evidence of left ventricular hypertrophy by the Estes scoring system, ${ }^{13}$ and all showed a strain pattern (table 1). A control group of 10 normal subjects (five men, five women; mean (range) age 58 (34-66) years) were also studied.

\section{ULTRASOUND EOUIPMENT}

A Vingmed CFM 750 ultrasound unit with 5 $\mathrm{MHz}$ and $2.5 \mathrm{MHz}$ mechanical transducers and a stand alone continuous wave Doppler transducer was used. The $5 \mathrm{MHz}$ transducer has a focal length of $40 \mathrm{~mm}$ with a lateral resolution of $0.6 \mathrm{~mm}$ and an axial resolution of $>0.3 \mathrm{~mm}$ operating at its nominal frequency. It is a broad bandwidth transducer allowing the transmission and reception of ultrasound frequencies over a wide range for both imaging and Doppler, enabling operation at a frequency of $6.3 \mathrm{MHz}$ in this study. A Doppler frequency of $4 \mathrm{MHz}$ was used enabling a Nyquist limit of $0.9 \mathrm{~m} / \mathrm{s}$ at the imaging depths used. The Vingmed CFM 750 unit incorporates a 512 line scan converter.

\section{STUDY PROTOCOL}

Patients gave informed consent. Patients were studied on the day before and 1 week after replacement of the aortic valve. The patient rested comfortably for 10 minutes and then haemodynamics were measured and echocardiography performed. Peak transvalvar aortic gradient, left ventricular mass index, left ventricular dimensions, and profiles of coronary flow velocity were recorded. The control group was studied on one occasion and profiles of coronary flow velocity recorded.

\section{HAEMODYNAMIC MEASUREMENTS}

Heart rate and systolic and diastolic blood pressure (SBP and DBP) were measured with a sphygmomanometer. Mean arterial blood pressure (MAP) was calculated from the formula: $\mathrm{MAP}=\mathrm{DBP}+(\mathrm{SBP}-\mathrm{DBP}) / 3$.

\section{PEAK TRANSVALVAR AORTIC GRADIENT}

Continuous wave Doppler was used to determine the flow velocity across the aortic valve. Apical, suprasternal, and right parasternal views were used to minimise the angle of incidence between the Doppler beam and flow allowing detection of highest transvalvar velocities. The highest velocity was judged from the optimal audio signal and spectral display. The peak instantaneous pressure gradient across the aortic valve was calculated with the modified Bernoulli equation: gradient $=4$ (velocity).$^{2}$

\section{LEFT VENTRICULAR MASS INDEX}

Left ventricular mass (LVM) was calculated from end diastolic left ventricular internal dimension (LVID) and posterior and septal wall thickness (PWT and IVST) on echocardiography by the Penn convention method with the formula: $L V M=1.04$ ((LVID +

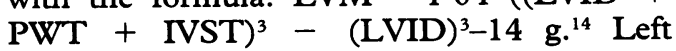
ventricular mass was indexed for body surface 


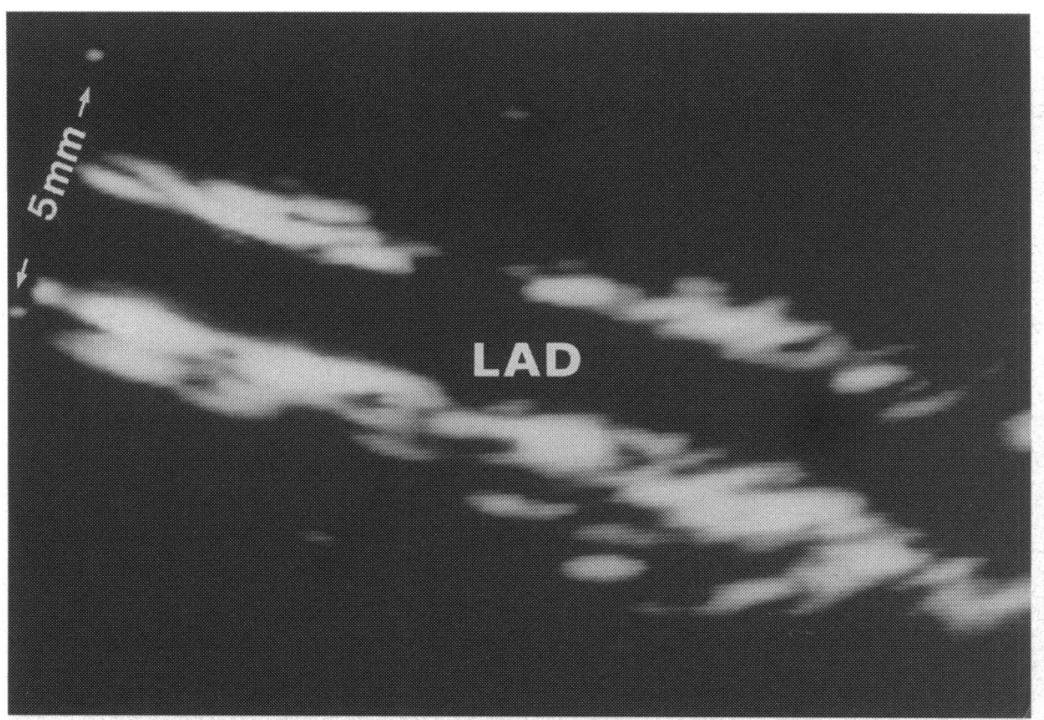

Figure 1 A longitudinal axis image by high frequency transthoracic Doppler echocardiography of the distal LAD in a patient with aortic stenosis.

area to provide a left ventricular mass index (LVMI).

\section{PROFILES OF CORONARY BLOOD FLOW}

VELOCITY

The technique of imaging the distal LAD and measuring blood flow velocities with high frequency transthoracic Doppler echocardiography has been described previously. ${ }^{112} \mathrm{~A}$ modified low left parasternal window and 5 $\mathrm{MHz}$ transducer were used to obtain long axis images of the left ventricle and the ultrasound beam was then angled laterally and superiorly to image the anterior interventricular groove. The distal LAD running in the interventricular groove lies only $2-4 \mathrm{~cm}$ from the chest wall and therefore well within the focal zone of high frequency transducers. This allows high quality imaging. All studies were performed by one operator (AK) and recorded on videotape for subsequent analysis.

Profiles of LAD blood flow velocity were recorded by placing a pulsed sample volume in the lumen of the distal LAD. Care was taken to record good quality narrow spectral traces with clean envelopes and a pure audio sound. The incident angle between the

Table 2 Haemodynamic data in patients before and after aortic valve replacement and in controls

\begin{tabular}{lcrrll}
\hline & & \multicolumn{2}{l}{ Patients } & \\
\cline { 3 - 4 } & Controls & \multicolumn{1}{c}{ Before } & \multicolumn{1}{c}{ After } & & p Value \\
\hline HR & - & $73(5 \cdot 2)$ & $79(4 \cdot 1)$ & NS \\
MAP & - & $104(5 \cdot 1)$ & $103(4 \cdot 2)$ & NS \\
SVp & $18(1 \cdot 1)$ & $14(0 \cdot 6)$ & $16(1 \cdot 7)$ & NS \\
SVm & $13(0 \cdot 9)$ & $11(0 \cdot 4)$ & $12(1 \cdot 7)$ & NS \\
DVp & $44(2 \cdot 8)$ & $39(2 \cdot 5)$ & $35(2 \cdot 1)$ & NS \\
DVm & $31(2 \cdot 4)$ & $27(1 \cdot 3)$ & $26(1 \cdot 7)$ & NS \\
TSF & $85(10)$ & $185(8 \cdot 5)$ & $90(12)$ & $<0 \cdot 01$ \\
TDF & $441(7 \cdot 2)$ & $480(6 \cdot 1)$ & $420(5 \cdot 2)$ & NS \\
DTP & $74(13)$ & $146(16)$ & $68(11)$ & $<0 \cdot 01$ \\
\hline
\end{tabular}

^Forward systolic flow $(\mathrm{cm} / \mathrm{s})$

+Wilcoxon signed rank paired test, differences between patients before and after valve replacement, and patients before operation and controls.

Abbreviations as for table 1, and TDF, time from onset of systole to start of diastolic flow (ms).
Doppler beam and direction of blood flow was noted for each patient and the same angle to flow used for the postoperative velocity recordings.

Velocity measurements were made with the internal measurement analysis package of the ultrasound unit. Systolic and diastolic peak and mean velocities were obtained by manual tracing around the spectral envelope. The time from onset of systole, taken as the $Q$ wave on the electrocardiograph, to the onset of forward systolic flow was measured. The time from the onset of diastolic flow to peak diastolic velocity was also measured. A mean of 10 measurements of each variable was made. Measurement of profiles of coronary flow velocity by this method has been shown to be reproducible with satisfactory between and within observer variability. ${ }^{15}$

\section{STATISTICAL ANALYSIS}

Values are mean (SEM). The differences between the control and aortic stenosis groups and between measurements before and after operation were compared with the Wilcoxon signed rank paired test. The strength of the association of these differences with other variables (peak transvalvar gradient, left ventricular mass index, and left ventricular dimensions) was assessed with the non-parametric Spearman correlation coefficient.

\section{Results}

Table 1 shows the characteristics of the study population. The mean (SEM) peak transvalvar gradient was $89(8 \cdot 5)$, range $48-130$ mm Hg. Mean (SEM) left ventricular mass index measured $261(30 \cdot 7)$, range 122-395 $\mathrm{g} / \mathrm{m} .^{2}$ High quality images of the LAD (fig 1) and Doppler spectral traces of coronary flow were obtained in all patients. The mean incident angle to flow measured $49^{\circ}(2 \cdot 1)$. In two patients the standard left parasternal views were not of sufficient quality to allow measurement of left ventricular dimensions and wall thickness.

COMPARISON WITH CONTROL GROUP

The control population showed normal biphasic, diastolic predominant, coronary flow with forward flow throughout systole (table 2). Reversed early systolic flow, mean velocity $20.6(3.6) \mathrm{cm} / \mathrm{s}$, was seen in six patients with aortic stenosis (fig 2A); only three of these patients had a history of angina. All but one of these six showed forward systolic flow late in systole. There was no obvious systolic flow in one patient before the operation. Peak and mean systolic and diastolic forward flow velocities were not significantly different between the control group and patients with aortic stenosis. The time from the start of systole to the onset of forward systolic flow was significantly longer in patients with aortic stenosis at $185(8.5)$ ms, compared with 85 (10) $\mathrm{ms}$ in the control population, $p<0.01$. This delay in onset of systolic flow was also seen in patients 
Figure 2 A Doppler spectral trace of flow in the $L A D$ in a patient with aortic stenosis $(A)$ before and (B) after replacement of the aortic valve.

Reversal of flow in early systole is seen before valve replacement (open arrow). Forward flow late in systole is shown (arrow). The figure is annotated to indicate the time measurements made: time interval 1 is the time from onset of systole to forward systolic flow (TSF): time interval 2 is the time from onset of systole to start of diastolic flow (TDF); time interval 3 is the time from onset of diastolic flow to peak diastolic flow (DTP).
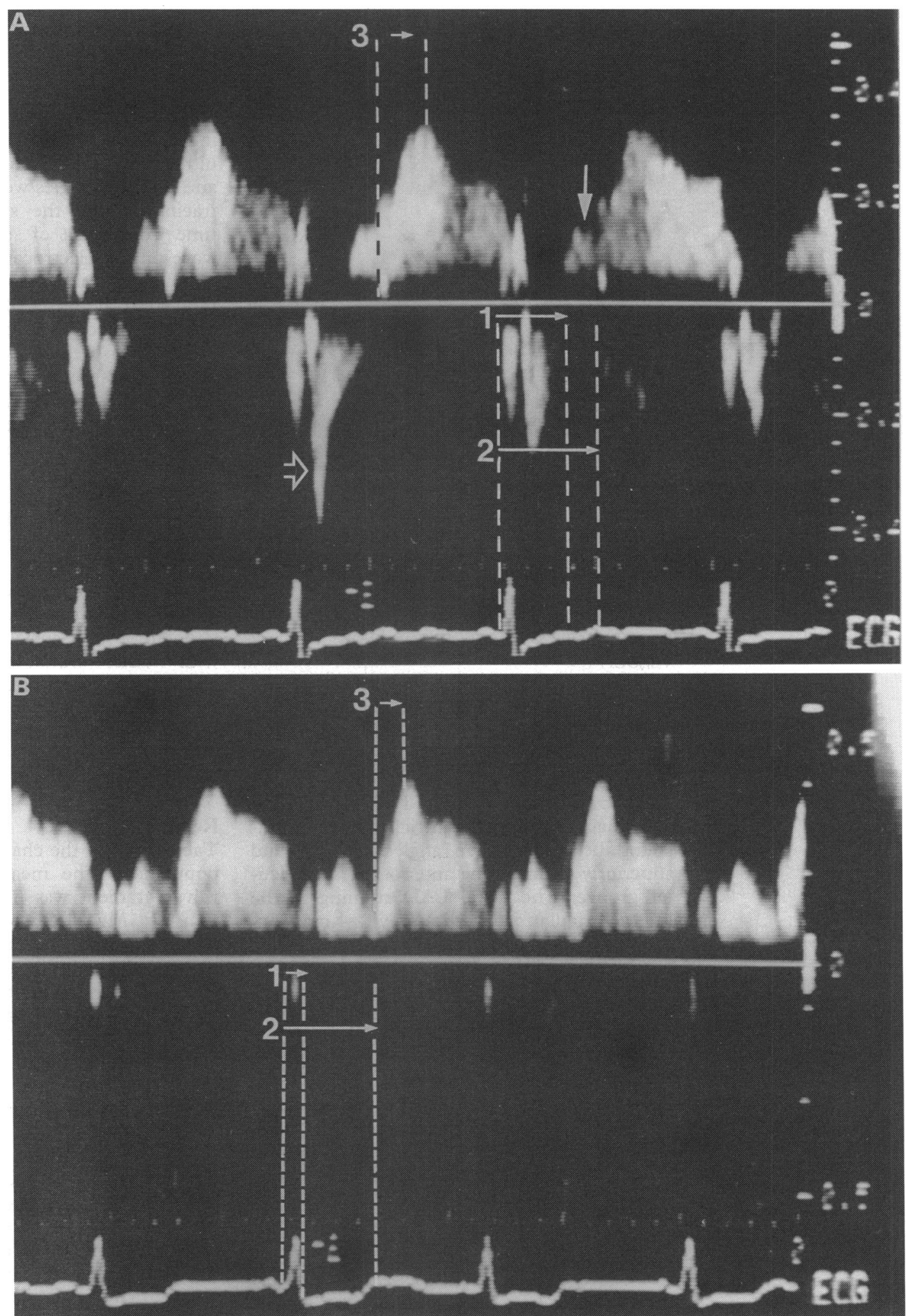

without reversed early systolic flow. There was no significant difference in the interval from the $Q$ wave on the electrocardiograph to the onset of the diastolic component of coronary flow between the two groups (480 $(6 \cdot 1)$ and $441(7 \cdot 2) \mathrm{ms})$. Diastolic coronary flow in aortic stenosis was characterised by a slow upstroke with a prolongation of the time from the start of diastolic flow to attainment of peak diastolic velocity compared with controls (146 (16) $v 74$ (13) ms, $\mathrm{p}<0.01)$.
EFFECTS OF REPLACEMENT OF THE AORTIC VALVE After valve replacement all patients showed forward flow throughout systole with coronary flow profiles similar to the control group (fig 2B, table 2). The time from the onset of systole to the start of forward systolic flow was significantly shorter after valve replacement (185 (8.5) ms before; 90 (12) ms after, $p<0.01)$. The interval from the $Q$ wave on the electrocardiograph to the onset of the diastolic component of coronary blood flow was unaffected (480 (6) ms before; 420 (5) $\mathrm{ms}$ 
after). The time from the onset of diastolic flow to peak diastolic velocity was also reduced after valve replacement; (146 (16) ms before; 68 (11) ms after, $\mathrm{p}<0.01$ ). Heart rate, MAP, and peak and mean systolic and diastolic forward flow velocities were not significantly altered by valve replacement. Only forward flow velocities were considered for estimation of peak and mean systolic values. There was no correlation between abnormalities in coronary flow patterns and preoperative symptoms, transvalvar gradient, left ventricular mass index, or ventricular dimensions.

\section{Discussion}

Angina pectoris is a frequent symptom in aortic stenosis in the presence of angiographically normal coronary arteries. ${ }^{2-4}$ Left ventricular hypertrophy due to pressure overload in aortic stenosis has been shown to be associated with significant abnormalities in coronary perfusion. Most studies have examined the coronary reactive hyperaemic response and shown considerable decreases in coronary reserve to the hypertrophied left ventricle in patients with aortic stenosis. ${ }^{5-7} \mathrm{By}$ contrast, coronary reserve in vessels that perfuse the non-hypertrophied right ventricle are nearly normal suggesting that hypertrophy is an important factor limiting coronary reserve. ${ }^{5}$ Similar decreases in coronary reserve were obtained in children with supravalvar aortic stenosis. ${ }^{16}$ The coronary vasodilator reserve in the left descending coronary artery was not significantly improved immediately after partial relief of obstruction of the aortic valve, suggesting that extravascular compressive forces are not responsible for the impairment found in coronary reserve. ${ }^{16}$ The decrease in coronary reserve in left ventricular hypertrophy induced by pressure overload has been attributed to inadequate growth of new vessels in relation to increase in myocardial mass. ${ }^{17}$ It is postulated that the abnormality in coronary reserve contributes to myocardial ischaemia in patients with aortic stenosis and normal coronary arteries. Replacement of the aortic valve in these patients, however, relieves symptoms of angina without regression of left ventricular hypertrophy. Also patients with aortic stenosis, left ventricular hypertrophy, and reduced coronary reserve often experience angina whereas patients with volume overload, left ventricular hypertrophy, and equally reduced coronary reserve typically do not. ${ }^{18}$ Other abnormalities of coronary flow must therefore be implicated in the pathogenesis of angina in patients with aortic stenosis.

The results of studies of coronary perfusion at rest in aortic stenosis have been conflicting. Animal studies suggest that cardiac hypertrophy secondary to a pressure load is associated with normal myocardial perfusion at rest. ${ }^{17}$ In patients with aortic stenosis, however, both normal and reduced left ventricular blood flow per unit mass at rest have been reported. ${ }^{19-21}$ Some studies have shown changes in transmural myocardial blood flow and metabolism, whereas others have not. ${ }^{22-25}$ As patients with aortic stenosis have changes in aortic and left ventricular pressures as well as left ventricular hypertrophy this could produce alterations in the dynamics of coronary blood flow. Replacement of the aortic valve in these patients should alter left ventricular and aortic haemodynamics and may correct abnormal flow patterns.

The aim of this study was to assess profiles of resting phasic coronary blood flow velocity in patients with aortic stenosis before and after replacement of the aortic valve and to determine whether changes in flow correlated with degree of left ventricular mass, transvalvar gradient, or ventricular dimensions. This is the first non-invasive study to examine the dynamics of coronary blood flow under physiological conditions in patients with aortic stenosis. Two invasive studies, one with an intravascular Doppler flow probe and the second an epicardial Doppler probe at the time of bypass surgery, have described waveforms of coronary blood flow velocity in patients with aortic stenosis. ${ }^{910}$ These studies, however, were performed in small numbers of patients under invasive conditions and may not accurately reflect the dynamics of resting coronary blood flow in aortic stenosis.

Methodological limitations have until recently hampered attempts at non-invasive measurement of coronary blood flow. It is now possible to image the distal LAD and measure profiles of coronary blood flow velocity with high frequency transthoracic Doppler echocardiography. ${ }^{112}$ This technique is easiest in patients with left ventricular hypertrophy. ${ }^{1112}$ The patients in this study, therefore, are ideally suited for examination by this technique. Definition of the morphology of the distal LAD by this method is compatible with that obtained by coronary angiography, ${ }^{12}$ and the technique is sensitive in detecting alterations in diameter of the LAD in response to pharmacological agents. ${ }^{26}$ It is the first method to allow non-invasive measurement of profiles of coronary artery blood flow under physiological conditions and repeated examinations may be easily performed. We have shown that measurement of profiles of coronary flow velocity by this method is reproducible with satisfactory within and between observer variability. ${ }^{15}$

We showed reversed early systolic flow and a significantly longer time from the onset of systole to the start of forward systolic flow in patients with aortic stenosis than in a normal control group. These findings are in keeping with patterns of coronary phasic flow obtained during cardiac surgery in patients with aortic stenosis. ${ }^{9}$ Reduced systolic flow but overall normal coronary flow per unit of myocardial mass has been shown in studies of animals with acute aortic stenosis. ${ }^{27-29}$ Reversed systolic flow has also been found in the proximal left coronary artery at coronary angiography in patients with aortic stenosis. ${ }^{30}$ In our study the reversed systolic flow disappeared and forward systolic flow started significantly earlier after valve replacement. By contrast, Fujiwara et al found reversal of 
flow at the end of systole after valve replacement in five out of six patients studied. 9 These findings, however, were made immediately after bypass and may reflect acute effects on the coronary capacitance vessels due to rapid changes in left ventricular wall and aortic root pressures.

The time from the onset of diastolic flow to peak diastolic velocity was also significantly longer in patients with aortic stenosis before valve replacement. The reduced rate of diastolic inflow in these patients may reflect diastolic dysfunction or increased resistance secondary to increased stress in the ventricular wall.

We did not show a correlation between abnormalities of coronary phasic flow and preoperative angina, left ventricular mass, transvalvar gradient, or ventricular dimensions. The numbers, however, are small and future studies in larger numbers of patients with varying degrees of severity of aortic stenosis may determine a relation between patterns of coronary flow in these patients and preoperative clinical, haemodynamic, and anatomical features. Similarly, a larger study population allowing comparison of groups with and without abnormalities of coronary flow is required to assess the significance of these factors in the pathogenesis of angina in patients with aortic stenosis.

\section{LIMITATIONS}

Although this technique gives a non-invasive, repeatable method of analysing coronary flow it is not possible to image the distal LAD in all patients. Success rates of between $30 \%$ to $80 \%$ have been reported in unselected populations and the technique is easiest in patients with good acoustic windows and left ventricular hypertrophy. ${ }^{11} 12$ An advantage is that high quality images of the LAD are obtained that may potentially allow quantitative measurements of coronary blood flow. The incident angle between the Doppler beam and direction of flow is large $\left(49^{\circ}\right.$ $\left(2 \cdot 1^{\circ}\right)$ in our study) which can lead to errors in determining absolute velocities. In our study, however, we are looking at changes within patients and therefore the absolute measurements are not as important as the relative changes.

In conclusion this is the first study to characterise phasic coronary blood flow in aortic stenosis under physiological conditions in the intact patient. Coronary blood flow velocities before valve replacement showed reversed early systolic flow, a delay in the onset of forward systolic flow and in attainment of peak diastolic velocity. The reversal of these features by replacement of the aortic valve may contribute to the relief of angina when left ventricular hypertrophy persists. Further studies are indicated to determine the relation between the abnormalities of coronary flow found and preoperative clinical and haemodynamic state.

\footnotetext{
1 Wood P. Aortic stenosis. Am f Cardiol 1958;1:553-71.

2 Graboys TB, Gohn PF. The prevalence of angina pectoris and abnormal coronary arteriograms in severe aortic valvular disease. Am Heart $f$ 1977;93:683-6.
}

3 Basta LL, Raines D, Najjar S, Kioschos M. Clinical, haemodynamic and coronary angiographic correlates of angina pectoris in patients with severe aortic valve disease. Br Heart ₹ 1975;37:150-7.

4 Moraski RE, Russell RO, Rackley CE. Aortic stenosis, angina pectoris and coronary artery disease. Circulation 1974;50 (suppl 3): 7 .

5 Marcus ML, Doty DB, Hiratzka LF, Wright CB, Eastham CL. Decreased coronary reserve: a mechanism for angina pectoris in patients with aortic stenosis and normal coronary arteries. $N$ Engl $₹$ Med 1982;307:1362-6.

6 Pichard AD, Gorlin R, Smith $\mathrm{H}$, Ambrose J, Meller J. Coronary flow studies in patients with left ventricular hypertrophy of the hypertensive type: evidence for an
impaired coronary vascular reserve. $\operatorname{Am} \mathcal{F}$ Cardiol 1981; 47:547-54.

7 Strauer BE. Ventricular function and coronary hemodynamics in hypertensive heart disease. $\mathrm{Am} \mathcal{F}$ Cardiol 1979;44:999-1006.

8 Fallen EL, Elliot WC, Gorlin R. Mechanism of angina in aortic stenosis. Circulation 1967;36:480-8.

9 Fujiwara T, Nogami A, Masaki H, et al. Coronary flow velocity waveforms in aortic stenosis and the effects of valve replacement. Ann Thorac Surg 1989;48:518-22.

10 Matsuo S, Tsuruta M, Hayano M, et al. Phasic coronary artery flow velocity determined by Doppler flowmeter catheter in aortic stenosis and aortic regurgitation. $A m \mathcal{F}$ Cardiol 1988;62:917-22.

11 Ross J, Mintz GS. Transthoracic two-dimensional high frequency $(7.5 \mathrm{MHz})$ ultrasonic visualisation of the distal left anterior descending coronary artery. $\mathcal{f} \mathrm{Am}$ Coll Cardiol 1990;15:373-7.

12 Kenny A, Shapiro LM. Transthoracic high frequency twodimensional echocardiography, Doppler and color flow mapping to determine anatomy and blood flow patterns mapping to determine anatomy and blood flow patterns
in the distal left anterior descending coronary artery. $\mathrm{Am}$ in the distal left anterior desc $1992 ; 69: 1265-8$.

13 Estes EH. Electrocardiography and vectorcardiography. In: Hurst JW, Logue RB, eds. The heart. New York: McGraw-Hill, 1974:304-6.

14 Devereux RB, Reichek N. Echocardiographic determination of left ventricular mass in man. Circulation 1977; 55:613-8.

15 Kenny A, Wisbey C, Shapiro LM. A reproducible noninvasive method of measuring left anterior descending coronary artery flow velocities. Am ₹ Cardiol 1993 (in press).

16 Doty D, Eastham C, Hiratzka L, Wright C, Marcus M. Determination of coronary reserve in patients with supravalvular aortic stenosis. Circulation 1982;66 (suppl I):I-186-92.

17 Marcus ML. Effects of cardiac hypertrophy on the coronary circulation. In: The coronary circulation in health and disease. New York: McGraw-Hill, 1983;285.

18 Hiratzka LF, Doty DB, Eastham CL, Marcus ML, White CW. Pressure versus volume overload has different CW. Pressure versus volume overload has different
effects on coronary reserve. Circulation 1982;66 (suppl II):II-354.

19 Johnson LL, Sciacca RR, Ellis K, Weiss MB, Cannon PJ. Reduced left ventricular myocardial blood flow per unit mass in aortic stenosis. Circulation 1978;57:582-90.

20 Bertrand ME, Lablanche JM, Thieuleux FP, Delforge MR, Carre AG. Coronary sinus blood flow at rest and during isometric exercise in patients with aortic valve disease: mechanisms of angina pectoris in the presence of normal coronary, arteries. Am $f$ Cardiol 1981;47: 199-205.

21 Rowe GG, Afonso S, Lugo JE, Castillo CA, Boake WC, Crumpton CW. Coronary blood flow and myocardial oxidative metabolism at rest and during exercise in subjects with severe aortic valve disease. Circulation 1965; 32:251-7.

22 Vinten-Johansen J, Weiss HR. Oxygen consumption in subepicardial and subendocardial regions of the canine aortic stenosis. Circ Res 1980;46:139-45.

23 Griggs DM Jr, Chen CC, Tchokoev VV. Subendocardial anaerobic metabolism in experimental aortic stenosis. Am f Physiol 1973;224:607-12.

24 Falsetti HL, Verani MS, Cramer JA, Carroll R. Total, phasic and regional myocardial blood flow in aortic phasic and regional myocardial blo
stenosis. Am Heart $\mathcal{1}$ 1979;98:331-8.

25 Attarian DE, Jones RN, Currie WD, et al. Characteristics of chronic left ventricular hypertrophy induced by subof chronic left ventricular hypertrophy induced by subcoronary valvular aortic stenosis. 1. Myocardial blood flow and 8 .

26 Ross J, Ren J-F, Land W, Chandrasekaran K, Mintz GS. Transthoracic high frequency $(7 \cdot 5 \mathrm{MHz})$ echocardiographic assessment of coronary vascular reserve and its relation to left ventricular mass. $\mathcal{F}$ Am Coll Cardiol 1990; 15:1393-7.

27 Delin NA. Systolic and diastolic coronary arterial blood flow in experimental valvular and subvalvular aortic stenosis. Scand $f$ Thorac Cardiovasc Surg 1969; 1 (suppl):5-54

28 Sabbah HN, Stein PD. Reduction of systolic coronary blood flow in experimental left ventricular outflow tract obstruction. Am Heart $\mathcal{f}$ 1988;116:806-11.

29 Pyle RL, Lowensohn HS, Khouri EM, Gragg DE, Patterson DF. Left circumflex coronary artery hemodynamics in conscious dogs with congenital aortic stenosis. Circ Res 1973;33:34-8.

30 Carroll RJ, Falsetti HL. Retrograde coronary artery flow in aortic valve disease. Circulation 1976;54:494-9. 